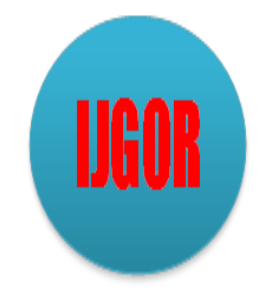

Available online at http://www.iorajournal.org/index.php/ijgor/index

International Journal of Global Operations Research

Vol. 1, No. 1, pp. 1-5, 2020

\title{
The Relationship Among Nutrition Knowledge, Vegetable Diet, Nutrition Status of Don Bosco Elementary Students, Manado
}

\author{
Laurensi Meity Sasube ${ }^{\mathrm{a}}$, Aldian Hein Luntungan ${ }^{\mathrm{b}} *$ \\ ${ }^{a}$ Faculty of Nursing, De La Salle Catholic University Manado, INDONESIA \\ ${ }^{b}$ Faculty of Public Health, Sam Ratulangi University Manado, INDONESIA \\ Corresponding Author: aldianhein@gmail.com
}

\begin{abstract}
Children in urban area tend to abandon healthy diet, since there are a lot of fast food options available around. In general, children valued the importance of nutrition, but they did not concern the health benefit of foods in food selections. Their dietary quality was not satisfactory, and the diet of most children did not meet the recommended serving requirements for vegetable, fruit, cereal and milk. The purpose of this study was to understand the relationship among Nutrition knowledge, vegetables diet and Nutritional Status of Elementary Students at Don Bosco Catholic School Manado. This is a cross sectional study in which we explored the nutritional status of Don Bosco Elementary Students based on nutrition knowledge, vegetable diet and Body Mass Index with questionnaire instrument, anthropometric measurements from June to August 2019. The nutritional status of Don Bosco Elementary School students based on body mass index (BMI) shows that students with normal and overweight nutritional status share an equal comparison that is 1:1 (50\%), while the level of student knowledge about nutrition was dominated by students with poor knowledge that is $67.7 \%$. This is also in line with the pattern of vegetables consuming which is also poor at $56.3 \%$. Based on the results of Chi-Square analysis there is no significant relationship between the levels of nutritional knowledge of students with vegetable consumption patterns. Conversely, there is no relationship between the levels of nutritional knowledge of students with nutritional status based on Body Mass Index (BMI).
\end{abstract}

Keywords: Nutrition knowledge, vegetables diet, Nutritional Status, Elementary Students 


\section{Introduction}

Indonesia currently faces two important problems related to nutrition, which are called double burden diseases. Namely under nutrition or poor nutrition and over nutrition or overweight, both are serious threats to the quality of children development. Incorrect in providing nutrition makes a child experiencing a disruption in their development. According to basic health research data in 2014 the trends in malnutrition problems pose a major challenge at the milestone of the child's age. At the same time Indonesia is dealing with an increasing prevalence of overweight children (11.9 - 14\%). Likewise, towards the end of childhood, when teenagers are 16-18 years old, the prevalence of obese adolescents has increased dramatically from 1.4\% in 2010 to $7.3 \%$ in 2013 (Simbolon et al, 2019). In our previous research about nutrition education to mothers with children of risk of malnutrition in Gangga Island, we found out that nutrition education for mother is very important to increase nutrition status of children at Gangga Island (Sasube \& Luntungan, 2018). This time we are going to measure the relationship among nutrition knowledge, vegetable diet and nutrition status of students at the urban area, which they tend to abandon healthy diet, since there are a lot of fast food options available around.

In general, children valued the importance of nutrition, but they did not concern the health benefit of foods in food selections. Their dietary quality was not satisfactory, and the diet of most children did not meet the recommended serving requirements for vegetable, fruit, cereal and milk (Lin et al, 2007; Adamo \& Brett, 2013). The habit of healthy eating in childhood and adolescence is important for proper growth and development, as well as for the prevention of chronic diseases that develop later in life such as cancer, cardiovascular disease and obesity (Hill et al, 2004; Sahoo et al, 2015), In US Dietary Guidelines for Americans 2015-2020, recommend that people aged 2 years or older follow a healthy eating pattern that includes a variety of fruits and vegetables, whole grains, fat-free and low-fat dairy products, protein foods and oils (WHO, 2003). Regular fruits and vegetable consumption has been linked to promoting a healthy weight and preventing chronic disease (Hang et al, 2004; Centers for Disease Control and Prevention, 2011) and interventions that focus on improving dietary behaviors can lead to an increase fruit in fruit or vegetable consumption (Pem \& Rajeewon, 2015; Duthie et al, 2017; Hodder et al, 2018).

The status and explanatory role of nutrition knowledge is uncertain in public health nutrition. Much of the uncertainty about this area has been generated by conceptual confusion about the nature of knowledge and behaviors, and, nutrition knowledge and food behaviors in particular. The main argument is that 'nutrition knowledge' is a necessary but not sufficient factor for changes in consumers' food behaviors (Worsley, 2002; Perez-Cueto, 2019). The purpose of this study is to understand the nutrition knowledge, vegetables diet, nutritional status and the relationship among them.

Nutrition knowledge is knowledge of nutrients and nutrition (Spronk et al, 2014; Nawaz et al, 2016). We can get the knowledge from social media, such as television, books, magazine, and news. However, we have to refer to the representative, credible and qualify sources to get the accurate knowledge. Students also can get the nutrition knowledge from teachers at school. In this research, we do not give any intervention to the students. It means basically the knowledge about nutrition comes from the social media and education at school.

Children tend do not like to choose vegetables in their menu due to their taste, and unattractive appearances in food presentation. It comes all to the effort of mothers to present vegetables in attractive way to make children interest on it. While nutritional status can give a description on children daily intake and the relationship with nutrition knowledge. However, many factors can influence the nutrition status of children such as mothers' knowledge about nutrition, behavior in choosing healthy food, children activities. Children as the asset of the Nations have gained more attention on their growth, especially in their daily intake of nutrition. Many irreversible condition such as stunting can affect children if they lack in nutrition since 'golden period' (0-5 years old) (Ramli et al, 2009; Martins et al, 2011; Pem, 2015). 


\section{Materials and Methods}

\subsection{Materials}

Materials that use in this research are weight and height scales, questionnaire, food model, liquid crystal display (LCD) and SPPS software.

\subsection{Methods}

This cross-sectional study, carried out in June-August 2019 at Don Bosco Catholic School Manado to evaluate the relationship among Nutrition Knowledge, Vegetables diet and Nutritional Status of Elementary Students. The questionnaire was administered to 96 students, ranging in age from 7-12 years. Nutrition knowledge and vegetable diet was evaluated with a 12 -question form concerning food composition and nutrition practices. Body weight was measured using an weight scale and height was measured using a height scale, and the average of those measurements was recorded. Univariate analyses for qualitative data were performed using Chi-square test, Fisher's exact test when necessary and multivariate logistic regression with $\mathrm{p}$ value $=0.05$.

\section{Results and Discussion}

The results indicated that children's with normal body mass index (BMI) was share the equal number $50 \%$ with overweight children. However, students' knowledge was poor in nutrition basics about $67.7 \%$, and also poor in vegetables consuming about $56.3 \%$ as seen in Figure 1 . Based on the results of statistical analysis using SPSS software shows that there is no significant relationship between the levels of nutritional knowledge of students with vegetable consumption patterns. Conversely, there is no relationship between the levels of nutritional knowledge of students with nutritional status based on Body Mass Index (BMI) (Figure 1).

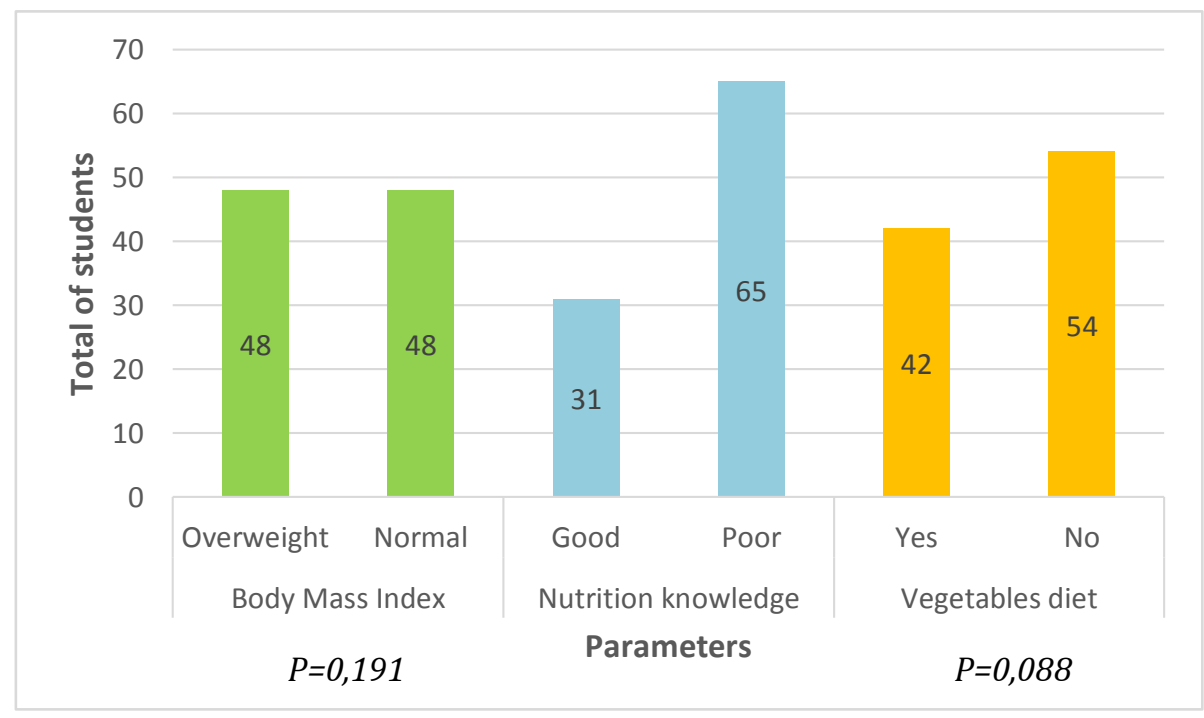

Figure 1: Overview of nutrition status, nutrition knowledge, vegetable diet at Don Bosco elementary students Manado, calculate using SPSS software. 
The prevalence of childhood obesity has increased dramatically in Indonesia (11.9 - 14\%). Likewise, towards the end of the age of children, which are teenagers 16-18 years, the prevalence of obese adolescents increased dramatically from $1.4 \%$ in 2010 to $7.3 \%$ in 2013 (Simbolon et al, 2019). The causes of being overweight and malnutrition are closely related. Children who experience growth retardation at an early age are at greater risk for being overweight later in life.

The number of children consuming non-nutritious food or junk food and fast food drinks also triggers the risk of being overweight. Physical activity and sedentary or inactive lifestyle contribute significantly to the increasing prevalence of chronic diseases such as diabetes and heart disease. Don Bosco School is located in the city center where there are many food stalls and snacks along the road and even in front of the school. In addition, children who attend Don Bosco are upper middle class where the allowance given by parents tends to be excessive, making children buy snacks and food more often in schools and surrounding areas. The habit of buying junk food and unhealthy snacks tends to be done by children with high economic status. With excessive allowance and lack of knowledge about healthy food, they often spend their pocket money by buying junk food that looks better and tastier than healthy food. The availability of junk food and fast food and easy access to get it has a big influence on children's behavior to choose food (Das, 2015).

Dietary practices during childhood not only play an important role in growth and development, they may also predict the occurrence of obesity, diabetes, and cardiovascular diseases in adulthood. As indicated in the result that most of the students have poor nutrition knowledge about $67.7 \%$, also poor in vegetable consumptions pattern about $56.3 \%$, than it is strongly recommended that in the future nutrition education for school children is necessary. The future nutrition education should not only include foodserving requirements of food groups, but also apply appropriate theories to improve motivation for healthy eating habits.

\section{Conclussion}

There is no significant relationship between the levels of nutritional knowledge of students with vegetable consumption patterns. Conversely, there is no relationship between the levels of nutritional knowledge of students with nutritional status based on Body Mass Index (BMI) of elementary students at Don Bosco Catholic School Manado.

\section{Acknowledgments}

This research supported by The Ministry of Research, Technology and Higher Education of The Republic of Indonesia on the Beginner Lecturer Research Scheme/ Penelitian Dosen Pemula (PDP) 2019.

\section{References}

Adamo, K. B., Brett, K. (2013). Parental Perceptions and Childhood Dietary Quality. Maternal and Child Health Journal, 18(4).

Centers for Disease Control and Prevention. (2011). Strategies to Prevent Obesity and Other Chronic Diseases: The CDC Guide to Strategies to Increase the Consumption of Fruits and Vegetables. Atlanta: U.S. Department of Health and Human Services.

Das, J. C. (2015). Fast Food Consumption in Children: A Review. Medical \& Clinical Reviews, 1(1). doi: 10.21767/2471-299X.1000001. 
Duthie, S. J., Duthie, G. G., Russell, W. R., Kyle, J. A. M., Macdiarmid, J. I., Rungapamestry, V., Stephen, S., Megias-Baeza, C., Kaniewska, J. J., Shaw, L., Milne, L., Bremmer, D., Ross, K., Morrice, P., Pirie, L. P., Horgan, G., Bestwick, C. S. (2017). Effect of increasing fruit and vegetable intake by dietary intervention on nutritional biomarkers and attitudes to dietary change: a randomised trial. European Journal of Nutrition, 57.

Hang, L., Jiang, R., Joshipura, K. J., Hu, F. B. (2004). Fruit and Vegetable Intake and Risk of Major Chronic Disease. Journal of the National Cancer Institute, 96(21), 1577-1584.

Hill, D., Nishida, C., James, W. P. T. (2004). A life course approach to diet, nutrition and the prevention of chronic diseases. Public Health Nutrition, 7(1A), 101-121.C

Hodder, R. K., Stacey, F. G., O’Brien, K. M., Wyse, R. J., Clinton-McHarg, T., Tzelepis, F., James, E. L., Bartlem, K. M., Nathan, N. K., Sutherland, R., Robson, E., Yoong, S. L., Wolfenden, L. (2018). Interventions for increasing fruit and vegetable consumption in children aged five years and under. Cochrane Database of Systematic Reviews. doi:10.1002/14651858.cd008552.pub4.

Lin, W., Yang, H. C., Hang, C. M., Pan, W. H. (2007). Nutrition knowledge, attitude, and behavior of Taiwanese elementary school children. Asia Pac J Clin Nutr, 2, 534-546.

Martins, V. J., Florencio, T. M. M., Grillo, L. P., Franco, M. C. P., Martins, P. A., Clemente, A. P. G., Santos, C. D. L., Vieira, M. F. A., \& Sawaya, A. L. (2011). Long-Lasting Effects of Undernutrition. International Journal of Environmental Research and Public Health, 8(6), 1817-1846.

Nawaz. M., Khalid, S., \& Ahmed, S. (2016). A Study to Assess Relationship Between Nutrition Knowledge and Food Choices Among Young Females. EC Nutrition, 6(1): 13-23.

Pem, D., Jeewon, R. (2015). Fruit and Vegetable Intake: Benefits and Progress of Nutrition Education Interventions- Narrative Review Article. Iran Journal Public Helath, 44(10), 1209-1221.

Pem, D. (2015). Factors Affecting Early Childhood Growth and Development: Golden 1000 Days. Journal of Advanced Practices in Nursing, 1(1).

Perez-Cueto, F. J. A. (2019). An Umbrella Review of Systematic Reviews on Food Choice and Nutrition Published between 2017 and 2019. Nutrients, 11(2398).

Ramli, Agho, K. E., Inder, K. J., Bowe, S. J., Jacobs, J., \& Dibley, M. J. (2009). Prevalence and risk factors for stunting and severe stunting among under-fives in North Maluku province of Indonesia. BMC Pediatrics, $9(64)$.

Sahoo, K., Sahoo, B., Choudhury, A. K., Sofi, N. Y., Kumar, R., Bhadoria, A. S. (2015). Childhood obesity: causes and consequences. Journal of Famili Medicine and Primary Care, 4(2), 187-192.

Sasube, L. M., \& Luntungan, A. H. (2018). The Impact of Nutrition Education on Mothers' Knowledge and Behaviour in Gangga Island, North Sulawesi. Prosiding in International Conference of Tropentag 2018, Belgium.

Simbolon, D., Yorita, E., \& Talib, R. A. (2019). The Risk of Hypertension in Adulthood as a Consequence of Adolescent Obesity. Kesmas: National Public Health Journal, 14 (1): 28-36. 
Spronk, I., Kullen, C., Burdon, C., \& O’Connor, H. (2014). Relationship between nutrition knowledge and dietary intake. Britis Journal of Nutrition, 111, 1713-1726.

World Health Organisation. (2003). Diet, Nutrition and The Prevention of Chronic Diseases: Report of a Joint WHO/FAO Expert Consultation. Geneva, Switzerland.

Worsley, A. (2002). Nutrition knowledge and food consumption: can nutrition knowledge change food behaviour? Asia Pacific J Clin Nutr, 11: S579-S585. 